\title{
Corrigendum: Progress in antiandrogen design targeting hormone binding pocket to circumvent mutation based resistance
}

\section{OPEN ACCESS}

Edited and reviewed by:

Rongtuan Lin

McGill University, Canada

${ }^{*}$ Correspondence: Jinming Zhou,

zhoujinming@imb.pumc.edu.cn

Specialty section:

This article was submitted to

Experimental Pharmacology and Drug

Discovery,

a section of the journal

Frontiers in Pharmacology

Received: 14 April 2015

Accepted: 20 April 2015

Published: 08 May 2015

Citation:

Tian X, He Y and Zhou J (2015)

Corrigendum: Progress in antiandrogen design targeting

hormone binding pocket to

circumvent mutation based

resistance. Front. Pharmacol. 6:97.

doi: 10.3389/fphar.2015.00097

\author{
Xiaohong Tian ${ }^{1}$, Yang $\mathrm{He}^{2}$ and Jinming Zhou ${ }^{2 *}$ \\ ${ }^{1}$ Lady Davis Institute, Jewish General Hospital, Mcgill University, Montreal, QC, Canada, ${ }^{2}$ Institute of Medicinal \\ Biotechnology, Chinese Academy of Medical Science, Beijing, China
}

Keywords: androgen receptor, antiandrogen, drug resistance, mutation, rational drug design

\section{A corrigendum on:}

Progress in antiandrogen design targeting hormone binding pocket to circumvent mutation based resistance

by Tian, X., He, Y., and Zhou, J. (2015). Front. Pharmacol. 6:57. doi: 10.3389/fphar.2015.00057

In the version of this article initially published online, there are two typos in Figure 3B, the "Atiandrogen design" should be "Antiandrogen design" and "ZINK" should be "ZINC." The correction has no impact on the results of the study or its conclusions. The corrected figure is given here.

Conflict of Interest Statement: The authors declare that the research was conducted in the absence of any commercial or financial relationships that could be construed as a potential conflict of interest.

Copyright (c) 2015 Tian, He and Zhou. This is an open-access article distributed under the terms of the Creative Commons Attribution License (CC BY). The use, distribution or reproduction in other forums is permitted, provided the original author(s) or licensor are credited and that the original publication in this journal is cited, in accordance with accepted academic practice. No use, distribution or reproduction is permitted which does not comply with these terms. 
A

Bulky group Strategy

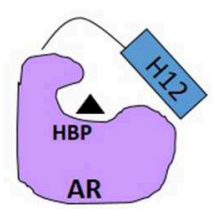

Agonist Binding

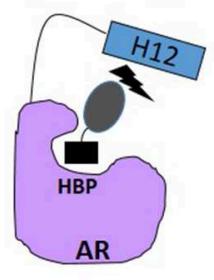

Bulky group Antiandrogen binding
B

Structure Based Antiandrogen Design

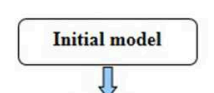

Model prediction

ภ

Experimental Verify $\sqrt{ }$

Antiandrogen design

Via Model prediction

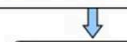

Biological Assay

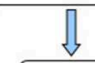

Leads

Molecular model in antiandrogen prediction

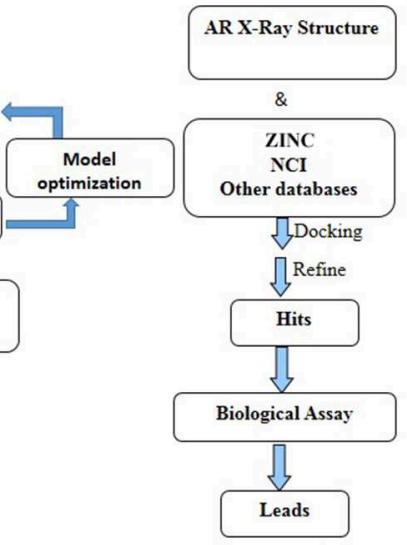

Structure-based virtual screening
C

\section{Conjugate Strategy}

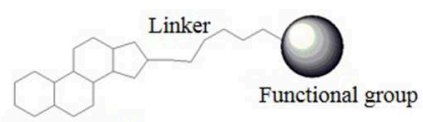

AR HBP Binder

Heterobifunctional construct

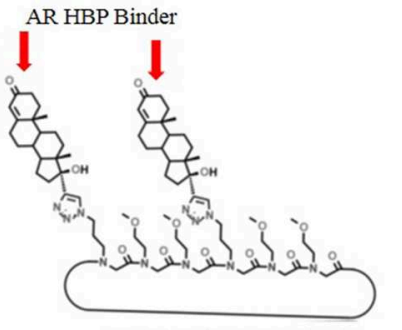

Multivalent construct

FIGURE 3 | Rational antiandrogen design strategy to combat the mutation driven drug resistance. (A) Bulky group strategy. (B) Structure based antiandrogen design. (C) Conjugate strategy. 